\title{
FESTIVAIS PARA QUÊ? AFETO E PERFORMANCE NA LITERATURA*
}

\section{Frederico Garcia Fernandes}

https://orcid.org/0000-0001-7852-9519

Como citar este artigo: FERNANDES, F. G. Festivais para quê? Afeto e performance na literatura. Todas as Letras - Revista de Língua e Literatura, São Paulo, v. 23, n. 1, p. 1-9, jan./abr. 2021. DOI 10.5935/1980-6914/eLETLT2114285

Submissão: janeiro de 2021. Aceite: fevereiro de 2021.

Resumo: Festivais literários fomentam uma politica cultural cujos desdobramentos irão recair na significação do texto literário, tanto por meio dos dispositivos de afeto quanto pelas performances dos autores. Este artigo analisa o impacto desses eventos na cultura literária brasileira e propõe uma reflexão sobre as relações entre performance e literatura, contribuindo para ampliar o debate sobre a mediação literária.

Palavras-chave: Festivais literários. Performance. Afeto. Flip. Estação Topolò. 


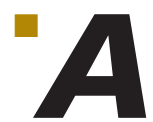

afirmação de que festivais de literatura impactam o sistema literário traz em suas sinuosidades inúmeras questões que merecem um olhar mais atento. Eventos dessa natureza têm tido um papel fundamental na disseminação de obras e escritores na contemporaneidade, desdobrando-se em problematizações sobre o valor de capital simbólico, o cânone literário, as relações entre literatura e sociedade, a arte e o espaço público, economia criativa, para citar alguns aspectos. O que este artigo objetiva demonstrar é que o fenômeno festival na contemporaneidade é franqueado tanto pela dimensão sociológica que os estudos de literatura comportam como há nele, também, uma dimensão performativa de grande relevância. Tal dimensão é dada pelos diferentes modos de como o texto chega ao leitor e as formas como ele o afetará. A compreensão da literatura a partir dos festivais recupera e amplia práticas de produção de sentido e de como eventos são responsáveis por franquear trânsitos literários.

A definição ad hoc para "trânsito literário" abarca um conjunto de ações e práticas que afetam público e autores durante o processo de circulação do texto literário. Algumas questões que permeiam esse processo merecem melhor atenção: como autor e público encontram-se em relação um com outro? Como tais relações entre poetas e autores se estabelecem e influenciam a prática literária? Ou, ainda, como entender a literatura quando ela é produzida no contato direto com o texto impresso ou pela performance poética? Ao buscar um entendimento sobre os festivais literários sob as lentes da afetividade, sobressaem-se alguns trabalhos de pesquisadoras brasileiras como Luciana di Leoné (2014) e Sandra Goulart Almeida (2011), que têm se debruçado sobre a literatura contemporânea. Em linhas gerais, apesar de se tratar de abordagens e objetos distintos, as autoras demonstram como, por meio do afeto, o texto literário apresenta o poder de modificar e deixar-se modificar, tornando-se um efeito. O afeto está para motivações, sensações corporais, experiências capazes de, conforme observa Almeida (2011, p. 311), intervir "na cidade ao instituir uma cidadania afetiva na tessitura social" e de transformar "a geografia emocional da cidade cosmopolita".

As observações sobre o afeto encontram uma conexão com o conceito de "máquina performática", desenvolvido pelos argentinos, estudiosos da literatura brasileira, Gonzalo Aguilar e Mario Cámara (2017, p. 11). Para eles,

A máquina performática é um dispositivo de aplanamento. Como ponto de partida, aplana a preeminência das textualidades, dos gêneros e das historicidades, originando-se na premissa de que nenhum signo é mais importante do que outro.

E ainda reiteram:

O campo experimental, resultado da máquina performática, constitui-se como conclusão de uma série de operações: abrir o texto a uma multiplicidade de conexões e construir uma sequência que recupere signos ínfimos e despercebi$\operatorname{dos}($ p. 11).

A reflexão sobre a máquina performática literária desloca a atenção para performances, declamações, formação de coletivos, índices de oralidade encontrados na escrita literária, formas de ocupação do espaço público por meio de intervenções, saraus e festivais literários. Sob tal prisma, a literatura não deixa de ser um dispositivo de afeto, em que o "elemento central são os corpos que 
tornam visiveis sua decisão de ocupar um lugar e dizer algo sobre si" (AGUILAR; CÁMARA, 2017, p. 134).

A compreensão da literatura como um dispositivo de afeto e uma máquina performática situa o foco da pesquisa literária no espaço público. Isso faz convergir para o centro de discussões a voz e o corpo, juntamente com a produção literária escrita. A investigação sobre festivais literários, além de propor um estudo sobre um campo ainda pouco explorado na Teoria Literária, tem como desdobramento a compreensão dos mecanismos de circulação do texto literário para além do livro, chamando a atenção para a performance, do modo como, por meio dela, significados de leituras podem ser modificados e singularidades espaçotemporais são atualizadas.

Os festivais literários, de acordo com teóricos da literatura que vêm se debruçando sobre o tema (GUERZONI, 2008; WEBER, 2018, entre outros), desempenham, em linhas gerais, o papel de fomentar uma politica cultural cujos desdobramentos podem recair na significação do texto literário, quer seja por meio dos dispositivos de afeto, quer seja pelas performances dos autores. As experiências individualizadas, isto é, de cada membro do público num festival, têm sido relevantes para o entendimento da literatura contemporânea, sua recepção e circulação. Tais experiências, na perspectiva de Millicent Weber (2018), contribuem para refletir sobre o engajamento entre leitores e escritores, possibilitando à academia repensar as oposições estabelecidas entre a literatura como mediada pelo livro e em situação de performance. Analisando mais de perto o fenômeno, o pesquisador australiano afirma que o festival literário não se diferencia de outros festivais culturais, apenas se enquadra como literário pelo fato de nele ser incorporada uma "cultura literária" (WEBER, 2018, p. 7). Como consequência, ao literary festival associa-se uma vasta gama de denominações, tais como: "festival do livro", "festival do livro da cidade", "festival de leitores", "festival de autores", "festa literária" e "festival de literatura", entre outros.

Maria Lillà Montagnani, Illaria Morganti e Maria Chiara Muti (2011) entendem os festivais como eventos que se destacam pela alta concentração de performances em um tempo-espaço determinado e possuem como desdobramento o fortalecimento das relações territoriais. Outra característica evidenciada na análise das autoras diz respeito ao envolvimento da comunidade por meio da construção de uma identidade cultural e da promoção do entretenimento, da miscigenação cultural e artística.

Festivais têm sido estudados pelo impacto territorial e pela ação político-estratégica para promover a revitalização urbana. É nesse sentido que Ludovico Solima e Federica Antonaglia (2008) aprofundam essa perspectiva por meio da compreensão dos chamados smart festivals. Os autores buscam dar um significado distinto de festival como suporte econômico e de enriquecimento local, algo bastante peculiar nas pesquisas iniciais de Guerzoni (2008), enaltecendo a melhoria na qualidade de vida por meio do acesso à educação, cultura e lazer. Segundo os autores:

Nossa definição para festivais inteligentes inclui todos os festivais que propõem conteúdos culturais elevados através do "formato festival": um canal excitante de entretenimento, numa linguagem compreensivel, em que a partilha e a fruição de dificuldades e os conteúdos elitistas tornam-se digeríveis, não através da suas simplificações, mas através do uso de espaços públicos mais agradáveis, de diferentes linguagens que são capazes de falar tanto para os públicos de alta 
e boa educação como para aqueles que estão presentes apenas para se entreter, divertir-se ou desfrutar de um evento incomum (SOLIMA; ANTONAGLIA, 2008, p. 12 , tradução nossa) ${ }^{1}$.

Os smartfestivals não são propriamente uma edição ou modalidade de festival, mas trata-se de um conceito ad hoc empregado na diferenciação do grau de integração entre o evento e a comunidade que o promove. O estudo traz uma guinada na perspectiva de compreensão e análise dos festivais literários, já que o foco se amplia ao levar em conta a linguagem literária e sua assimilação, bem como a apreensão de conteúdos por parte do público local. Para Solima e Antonaglia (2008), um festival torna-se "inteligente" ao promover intervenções estratégicas no espaço urbano, o que, em termos práticos, traduz-se na melhoria da qualidade de vida da comunidade por meio da criação de alternativas de geração de renda e reocupação/restauração de espaços então degradados. Não se trata de um evento cujo impacto possa ser mensurado, apenas, por meio do número de visitantes e de seu apelo turístico: o festival promove mudanças internas na própria comunidade que o produz e isso se contabiliza também na assimilação de linguagens inovadoras e na qualidade do debate intelectual, aproximando indivíduos numa ação comum de cidadania.

Os resultados positivos a que um festival pode chegar não deixam de ser afetados pelas tensões e disputas de ordem estética, política e econômica que cercam eventos dessa natureza. É a compreensão de como os embates pertinentes ao campo literário são exercidos que revela bastante sobre a identidade do festival. A recorrência e a importância do festival ${ }^{2}$ como um fenômeno da indústria do entretenimento têm levado escritores e outros agentes literários a trabalhar com múltiplos sistemas de produção cultural. Festivais são gestados em ambientes artísticos multissistêmicos nos quais artistas e visitantes são instigados a dialogar com expressões de temporalidades, espacialidades e identidades distintas.

Como bem observou Millicent Weber (2018, p. 30), um "festival literário" assenta-se numa relação de interesses concorrentes, abrindo-se para o debate sobre poder cultural, econômico e político, formando opiniões sobre o próprio contexto cultural, econômico e político no qual são gerados. Nas palavras do autor,

[...] o festival literário não tem sido entendido como uma referência nos debates literários, embora opere, num sentido amplo, como como um significante para o campo literário. Os festivais literários são espaços em que autores e leitores se identificam entre si e em que esses autores e leitores, ao lado de editores, diretores de festivais, governos e patrocinadores, competem por legitimidade por meio da aquisição de capital cultural, social e econômico ${ }^{3}$ (WEBER, 2018, p. 32 , tradução nossa).

1 No original: "Our definition for smart festivals includes all those festivals in which there has been exposure and which propose high cultural contents through the 'festival format': an amusing and exciting channel that speaks in a more comprehensible language, in which the sharing and the fruition of difficult and elitist contents become easier, not through simplification of the shared contents, but rather through the use of more relaxing and public spaces and through the use of different languages that are able to speak to both high and well-educated publics as well as to those that are present just to relax, to be entertained, or to enjoy an unique event".

2 Para se ter uma ideia, no ano de 2013, a Itália foi palco de 927 festivais em diferentes áreas artísticas e do saber, sendo o período de maior concentração o trimestre junho-julho-agosto, que corresponde às férias de verão no continente europeu.

3 No original: "[...] the literary festival is no longer understood to represent a particular position in literary debates, but operates rather as a signifier for the literary field more broadly. Literary festivals are spaces in which authors and readers identify themselves and one another and in which these authors and readers, alongside publishers, festival directors, governments, and sponsors, compete for legitimacy through the acquisition of cultural, social, and economic capital". 
Ao serem trazidos para o debate da crítica literária, os festivais posicionam-se no centro das tensões entre o capital simbólico, cultural e econômico do campo literário. Eles desempenham um papel tanto na circulação como na constituição de repertórios literários. Isso não deixa de ser uma constatação do fenômeno literário cabivel ao modelo das Regras da arte, de Pierre Bourdieu (1996). Entendida nessa perspectiva, a análise de um festival permite que sejam descortinadas percepções acerca de ambientes comunicacionais, possibilitando formas de expressão que vão produzir um modus literário. A obra, fruto de um experimento ainda novo, nasce orientada para um tipo de palco metafórico no qual competirá por sua visibilidade.

Ainda como pondera Bourdieu (1996), o processo de legitimação e de acumulação de capital simbólico e econômico de uma obra literária encontra-se atrelado a instituições, mercados, produtos e repertórios, catapultando o sistema literário para além da ideia de um "gênio criador". Os festivais são um dos ambientes onde a ação de seus agentes tem por princípio a redefinição de uma ordem dentro de um sistema de produção cultural, em que os vínculos com participantes passam por uma rede de afetos.

Refletir sobre essa rede de afetos implica compreender a identidade de um festival, de modo a avançar para além do discurso apologético enraizado na ideia de "um negócio em que todos ganham". Para uma definição ad hoc de identidade de um festival estamos considerando as formas de dar visibilidade ao evento e de como ele é concebido por seus organizadores, que, em certo sentido, estão cientes dos conflitos de ordem estética, política e econômica que sua proposta de festival dimensiona. Questões como a profundidade com a qual o evento se integra à cultura local, o grau de irreverência e a dessacralização de instituições ou personalidades do campo literário ou acadêmico, a crítica ou favorecimento a práticas comerciais, a origem dos patrocinios e financiamentos, bem como o número de participantes são indicadores que delineiam a identidade de um festival.

Durante uma pesquisa de campo na Itália, conduzida em 2014, dois eventos chamaram nossa atenção quanto aos aspectos de sua identidade e servem para ilustrar o campo de tensões em que um festival pode ser organizado ${ }^{4}$. O Festivaletteratura de Mântova, realizado desde 1997, na Lombardia, conta com atrações pagas e algumas gratuitas. O comércio de bens culturais - como livros, CDs, palestras, por exemplo - divide o espaço público da realização da festa com tendas e estandes responsáveis pela divulgação e comercialização de gêneros alimentares, aparelhos eletrônicos, automóveis, utensílios domésticos, entre outros produtos. A parceria com empresas e marcas consolidadas no mercado transmitem ao festival a reputação de um evento bem-sucedido da perspectiva comercial, sendo isso um divisor de opiniões no meio artístico e literário. O sucesso comercial pode ser responsável por retroalimentar outro aspecto do evento: a presença em massa de turistas e visitantes. O Festival de Mântova apresenta a estrutura de um grande evento, um esquema de assessoria de imprensa divulgando suas atrações e seu espaço na grande mídia e apoio logístico, com ônibus de outras cidades disponibilizados exclusivamente para atender ao público do

4 Trata-se da pesquisa "A poesia do espaço público: polissistemas literários e estratégias de inserção social do texto poético", realizada junto à Universidade de Bolonha, sob supervisão do dr. Roberto Vecchi, entre março de 2014 e março de 2015 . Uma primeira síntese de seus resultados foi publicada no artigo "Festivais literários, sistemas culturais e marketing territorial: um estudo de caso italiano" (FERNANDES, 2014). 
evento. Nele trabalham centenas de voluntários, que dividem as funções com o pessoal contratado. O público visitante, no ano da pesquisa (2014), foi estimado em 119 mil pessoas.

O Estação Topolò é certamente um contraponto ao Festival de Mântova. Surgido em 1993 nos confins do nordeste italiano, caracteriza-se pela valorização de artes performáticas e experimentais, bem como pela integração de poetas e artistas com a língua e história local. As atividades do festival são totalmente gratuitas. A longo de suas edições, o público do Estação Topolò chegou a ser estimado em 1.400 participantes, mas seus organizadores sinalizavam, ao contrário do de Mântova, para a necessidade de diminuir esse número, de modo a não torná-lo um evento de massas. O Estação Topolò é intitulado pelos próprios organizadores como um "antifestival", no sentido de não se enquadrar no modelo gerencial de negócios, com abertura para o mundo empresarial, como é o de Mântova.

No Brasil, nos últimos anos, festivais literários e saraus têm chamado a atenção da mídia e de órgãos de fomento à cultura devido ao aumento de ocorrências e por se tratar de eventos que têm atraído muitos jovens. A Coordenação Geral de Livro, Leitura, Literatura e Economia do Livro (CGLEL), do Departamento de Livro, Leitura, Literatura e Bibliotecas (DLLLB), órgão vinculado à Secretaria Especial da Cultura (SEC), do Ministério da Cidadania, realizou, em 2017, um levantamento de feiras e festivais literários, atualizado em janeiro de 2019, em que foram cadastrados 222 eventos, compreendendo "feiras", "festas literárias" e "festivais" . O exame mais atento da planilha de eventos literários organizada pela CGLEL indica que um festival literário pode compreender desde uma feira de livros, um evento em homenagem a algum escritor, uma programação com apresentações artísticas, instalações literárias até performances poéticas e concurso literário com premiação. Tanto aqui como na Itália, os festivais podem estar voltados para o atendimento de uma demanda turística, com a participação de personalidades da grande mídia e comercialização de produtos, ou, numa perspectiva avessa, se definirem como antifestivais.

Festivais tendem a se fazer visiveis por meio do prestígio e posicionamento político de seus convidados, dos números de movimentação financeira e de público, da badalação dos locais onde são realizados, da repercussão na mídia e da forma como o popular é apropriado por discurso erudito e intelectualizado. No Brasil, um dos festivais que poderia ser chamado, no jargão empresarial, de "case de sucesso" é sem sombra de dúvidas a Festa Literária Internacional de Paraty (Flip). Isso pode ser corroborado pelos inúmeros festivais espalhados em várias cidades brasileiras cujas siglas remetem a uma ideia de franquia da Festa Literária Internacional de Paraty. Flib (em Bonito, no coração do Pantanal), Flim (em Maringá, no Paraná), Flima (na Mantiqueira), Flic (na Chapada dos Guimarães), Flimo (em Morretes, no Paraná), Fliporto (em Porto de Galinhas, depois Olinda e Recife), Flist (no bairro de Santa Teresa, no Rio de Janeiro), Flij (em Jundiaí), Flipa (na Ilha de Paquetá, no Rio de Janeiro) são alguns exemplos de eventos que trazem em seus títulos o prestígio da internacionalização e o apelo ao turismo.

5 Esse levantamento foi obtido por meio de correspondência eletrônica com Nelma Elisa Freiras, agente administrativa da CGLEL/ DLLLB/SEC/Ministério da Cidadania. Dados confrontados com reportagem do jornal O Globo, de 2015, quando os festivais se encontravam sob responsabilidade da pasta do antigo Ministério da Cultura, demonstram haver um decréscimo no número desses eventos no País, já que, conforme a matéria, no ano de 2013 foram registrados 257 eventos dessa natureza e, no ano subsequente, 320. 
O escritor João Anzanello Carrascoza (2019), a despeito de sua experiência na Flip, destaca alguns aspectos que merecem uma reflexão. Segundo ele,

Uma das críticas recorrentes nos artigos que lemos sobre a FLIP nas reuniões mensais do grupo de pesquisa, e com as quais concordávamos, era o caráter "invasivo" da FLIP em Paraty: na "grande tenda" se desdobrava uma programação voltada unicamente para o público externo, que para lá se deslocava, sem compromisso com o patrimônio histórico da cidade. À população local, incapaz de pagar o preço dos ingressos, nada era oferecido senão o esquecimento - a instalação de telões na rua, que reproduziam o que se passava no palco da grande tenda, embora louvável, jamais diminuiria o abismo entre os habitantes de uma das cidades mais violentas do Estado do Rio de Janeiro e os escritores convidados (brasileiros e estrangeiros) que abandonavam seus gabinetes para serem ouvidos por centenas de pessoas (vindas de todos os cantos do país) num espaço confortável. Outras ressalvas: a predominância de autores publicados por uma única e grande editora, a cobertura "espetacular" da Rede Globo, o silêncio em relação às temáticas das minorias, o culto aos troféus do campo literário (CARRASCOZA, 2019, p. 5).

Carrascoza vai aos poucos dissolvendo as tensões da Flip ao comentar suas experiências na Flipzona e Flipinha. Em sua opinião, o festival contribui para solidificar uma rede de profissionais da literatura, o que irá fortalecer os vínculos artísticos e profissionais entre os participantes e, também, criar afinidades com grupos e comunidades locais. Focando a sua participação, em julho de 2015, junto à Flipinha (evento paralelo à Flip voltado para a interação entre escritores e alunos de escolas que compõem o arquipélago paratiense), o autor assevera: "observando os agentes de leitura que estiveram comigo, encontro a definição de literatura - que vou repetir pelos anos seguintes: rede de afetos" (CARRASCOZA, 2019, p. 21, grifo nosso). O afeto tem a ver com contágio, com a maneira como sujeitos estabelecem trocas comunicacionais e como essas trocas têm como desdobramento um ato criativo. Uma rede diz respeito a conexões estabelecidas entre público e autor ou entre autores num festival; trata-se de uma esfera de relações artístico-profissionais em que seus membros contribuem mutuamente para dar visibilidade a seus trabalhos. A rede de afetos converge para um mesmo núcleo a possibilidade de conexão e de criação.

Essas práticas consubstanciam-se nos (re)encontros com escritores e agentes literários, nos poemas feitos por crianças de uma escola municipal a partir do livro Prendedor de sonhos, de Carrascoza. Lido a partir dessa experiência, o depoimento do escritor sobre sua participação na Flipinha não ilustra os conflitos e tensões entre os moradores locais e a festa literária, mas a própria Flipinha pode ser entendida como uma reação dos organizadores às críticas feitas à Flip. Considerada um evento de grande abrangência de público, com visibilidade internacional, parceiros comerciais consolidados na produção de bens culturais e patrocinadores públicos, a Flip tornou-se uma espécie de vitrine dos festivais no Brasil. Consequentemente, a festa não está imune a questionamentos, já que movimenta uma disputa pelo capital simbólico, cultural, social e econômico. A Flipinha, dessa forma, pode ser entendida como uma tentativa de neutralizar críticas de que o evento não atinge a população periférica de Paraty.

Além disso, a Flip não raramente é tomada como um festival literário comercial, preocupado com a atração de turistas, por meio de uma programação que 
conta com celebridades como prêmios Nobel, publicados por grandes editoras brasileiras ou personalidades artísticas famosas. Sua organização, que compreende a administração do evento, como contratação de funcionários e logística, está a cargo da Associação Casa Azul, uma empresa sediada em São Paulo, voltada para a requalificação urbana a partir de iniciativas culturais. O arquiteto Mauro Munhoz, idealizador da Flip e presidente da Associação Casa Azul, ao agregar a literatura ao urbanismo, acaba por trazer as tensões dos dois campos para o centro de discussão da Feira Internacional: o do prestígio literário e a ocupação do espaço público e arquitetônico de Paraty.

Nesse sentido, o movimento de tensão simbólica, cultural e econômica parece ser bastante evidente quando, numa atividade paralela à própria Flip, editoras independentes promovem um antifestival às margens do Perequê-Açu, fora do centro histórico de Paraty. Denominado Festa Literária Pirata das Editoras Independentes (Flipei), o evento pauta-se pelo posicionamento político, tendo como foco a crítica ao liberalismo e ao fascismo intensificados no atual contexto político brasileiro. A Festa Pirata define-se como um movimento antípoda à Flip, uma vez que enquanto de uma margem do Perequê-Açu encontram-se as celebridades literárias, na Flipei os convidados são não menos célebres, mas caracterizam-se pelo debate político e o engajamento da arte.

Flipei e Estação Topolò são dois exemplos de como os festivais se tornam reações a grandes eventos culturais. Eles surgem motivados pelo questionamento do capital simbólico e econômico que envolvem o campo literário. No entanto, não deixam de revelar estratégias de afirmação de prestígio de determinados autores e intelectuais, bem como de obtenção de resultados de impacto social - e também financeiro - que justifique sua realização. O antifestival é a marca de um protesto, cujo entretenimento e a rede de afeto constituída pelo e ao longo do evento apresentam resultados mais ou menos comuns em relação às festas literárias internacionais. No entanto, a diferença de público que circula nesses eventos, dada sobretudo pelo posicionamento ideológico em relação aos conteúdos e questionamentos sobre o capital simbólico, desdobrados em questões de ordem estética e política, aciona o gatilho de construção de identidade dos festivais. O corolário disso é que a máquina performática, operada por seus atores, revelará processos criativos também distintos, os quais retroalimentam o sistema literário.

Festivais e antifestivais tornam-se eventos agenciadores da promoção e da transformação do próprio sistema no qual se inserem - no caso, a literatura. Eles são um fenômeno rico para a compreensão da produção literária na contemporaneidade, já que deixam em evidência estratégias de seus agentes na disputa por prestígio no campo literário.

Há na performance do festival várias implicações que se refletem na forma de como o espaço público está sendo ocupado, como são estabelecidos vínculos comunitários e como as escolhas da curadoria dimensionam um perfil de público. O festival, ao convergir obra, autor e público para um mesmo espaço e tempo, cria um fluxo de sentido capaz de deixar marcas no texto literário, tornando-o único em seu momento de recepção. É essa dimensão performática dos festivais, dada pela forma como escritores, público e produtores afetam-se mutuamente, um dos elementos-chave para a compreensão do fazer literário. Como bem observou Paul Zumthor (2000, p. 40), a performance encontra-se conectada ao conhecimento que transmite e, por isso, o afeta e o modifica, deixando de ser um 
simples meio de comunicação para se tornar um "modo vivo de comunicação", ou seja, eficaz e dinâmico.

Festivais, portanto, cumprem o papel de uma dinâmica de transmissão poética que persiste, considerando suas variações e formatos de organização, desde a Antiguidade. A performance permite ao texto literário uma materialização, abrindo a escrita para o engajamento do corpo e para a palavra-voz.

\section{Why festivals? AFfection and Performance in literature}

Abstract: Literary Festivals foster a cultural policy whose repercussions will affect the meaning of literary text through affection dispositive and authors' performances. This article deals with the impact of these events in Brazilian literary culture and proposes a reflection on the relationship between performance and literature, increasing literary mediation debate.

Keywords: Literary festivals. Performance. Affection. Flip. Stazione di Topolò.

\section{REFERÊNCIAS}

AGUILAR, G.; CÁMARA, M. Máquina performática: a literatura no campo experimental. Tradução Gênese de Andrade. Rio de Janeiro: Rocco, 2017.

ALMEIDA, S. R. G. O poder da escrita: gênero, espaço e afeto na literatura contemporânea. Revista Cerrados, v. 20, n. 31, p. 297-314, 2011.

BOURDIEU, P. As regras da arte: gênese e estrutura do campo literário. Tradução Maria Lucia Machado. São Paulo: Companhia das Letras, 1996.

CARRASCOZA, J. A. Encontro do sonhador e do cientista em terra firme. São Paulo, 2019. Texto inédito.

FERNANDES, F. Festivais literários, sistemas culturais e marketing territorial: um estudo de caso italiano. Nonada Letras em Revista, v. 2, n. 23, p. 20-33, 2014.

GUERZONI, G. Effeto Festival: l'impatto economico di festival di approfondimento culturale. [s. 1.]: Fondazione Casa di Risparmio Della Spezia/Fondazione Eventi, 2008.

LEONÉ, L. di. Poesia e escolhas afetivas: edição e escrita na poesia contemporânea. Rio de Janeiro: Rocco Digital, 2014. E-book.

MONTAGNANI, M. L.; MORGANTI, I.; MUTI, M. C. The phenomenon of Art Festivals: an empirical and legal analysis. Quaderni ASK, v. 5, p. 1-18, 2011.

SOLIMA, L.; ANTONAGLIA, F. Demand analysis of "smart" festivals. A longitudinal comparison. In: WORKSHOP ON MANAGING CULTURAL ORGANISATIONS, 3., 2008, Bolonha. Anais [...]. Bolonha, 2008. p. 1-28.

WEBER, M. Literary festivals and contemporary book culture. Canberra: Palgrave McMillan, 2018.

ZUMTHOR, P. Performance, recepção, leitura. Tradução Jerusa Pires Ferreira; Suely Fenerich. São Paulo: Educ, 2000. 